\title{
Bibliocanta
}

\section{A Biblioteca sob o olhar da comunidade escolar}

Pereira ${ }^{1}$, Ismael Soares ismael@emcm.ufrn.br

Resumo: Apresenta a visão dos alunos do Ensino Fundamental II e o posicionamento dos professores e da gestora a respeito da necessidade de implantação da biblioteca numa determinada escola pública, situada na cidade de João Pessoa. Trata-se de um estudo qualitativo de nível descritivo, onde a coleta de dados foi concebida mediante aplicação de questionários a 35 (trinta e cinco) alunos do $6^{\circ}$ ao $9^{\circ}$ ano, a cinco professores e à gestora da escola. Os resultados mostram que o grupo pesquisado almeja a construção de uma biblioteca na instituição de ensino. Essa deve ser bem estruturada, oferecer serviços diversificados ao apoio pedagógico, permitir o acesso às tecnologias de informação e gerenciada por bibliotecários. Conclui-se que, para a implantação de bibliotecas nas escolas públicas, é necessário o apoio dos governantes no sentido de destinarem mais recursos financeiros às reformas e ampliações das dependências pedagógicas.

Palavras-chave: Biblioteca escolar. Dependências pedagógicas. Bibliotecários. Estudo de usuários.

\section{INTRODUÇÃO}

A educação pública no Brasil ainda é muito carente de recursos que proporcionem auxílios aos estudantes na esfera do ensino e aprendizagem, principalmente no tocante à educação básica. Tem-se como um organismo de apoio aos discentes nesse processo de formação socioeducacional, a biblioteca escolar.

Esse tipo de biblioteca tem uma importante missão enquanto centro de informação e educação, a qual consiste em habilitar os estudantes para a aprendizagem ao longo da vida e a desenvolver a imaginação, preparando-os para viver como cidadãos responsáveis (MANIFESTO, 2000). A biblioteca escolar é um recurso fundamental no desenvolvimento dos processos ensino e aprendizagem

\footnotetext{
${ }^{1}$ Bacharel em Biblioteconomia pela Universidade Federal da Paraíba e Bibliotecário-Documentalista no Instituto do Cérebro, UFRN. Lattes: http://lattes.cnpq.br/1729110267640248
} 


\section{DBibliocantos}

com qualidade, além de ser um espaço relevante de apoio didático-pedagógico e cultural.

Seguindo essa concepção de ensino-aprendizagem, Behr, Moro e Estabel (2008, p. 32) afirmam que: "[...] a gestão em serviço de bibliotecas escolares deve priorizar a aprendizagem em todo o processo de desenvolvimento humano, além do acesso e uso da informação". Já Ely (2004, p. 46) descreve que "a biblioteca escolar é o local onde se inicia a formação de hábitos e atitudes, bem como o desenvolvimento de habilidades e capacidades para sua adequada utilização. Contribui também para a frequência futura a outros tipos de bibliotecas". A partir daí observa-se a importância da implantação de uma biblioteca com recursos materiais e humanos adequados para melhor servir a comunidade escolar.

Além da inexistência de bibliotecas nas escolas públicas, a maioria não dispõe de profissionais habilitados, capazes de gerir da forma correta esses espaços. Muitas vezes esses ambientes são administrados por professores impossibilitados de exercer sua função de educador ou outros profissionais da instituição que necessitam de realocação para outro setor por algum motivo. Macedo (2005, p. 68) afirma que:

[...] os pontos críticos, todavia, não recaem tão-somente na inexistência da biblioteca escolar, mas na sua precariedade: ou é "arremedo de biblioteca escolar", sem organização, confusa, e que não pode servir de modelo para o uso correto da informação, ou não conta com alguém motivado para dinamizar a prestação de serviços bibliotecários.

Baseado nessas considerações pode-se afirmar que a biblioteca escolar dificilmente cumprirá seu papel de forma satisfatória se não for gerenciada por um profissional habilitado ao cargo, tal como o bibliotecário. Esse profissional irá desempenhar, nesse ambiente, variados afazeres no âmbito educativo e sociocultural conforme relato de Corrêa et al. (2002, p. 121):

[...] o bibliotecário desempenha algumas funções educativas, contudo diferentes das que um educador escolar desempenha em sala de aula. Sua função educativa concentra-se no sentido de auxiliar a comunidade escolar na utilização correta das fontes de informação, 
dando um embasamento para que o educando saiba usufruir esses conhecimentos, também fora do ambiente escolar. Ele ensina a socialização, através do compartilhamento de informações, de utilização de materiais e ambientes coletivos, preparando assim o educando no desenvolvimento social e cultural.

Analisando os benefícios que uma biblioteca bem administrada e estruturada pode gerar no contexto socioeducacional da comunidade escolar, pode-se fazer a seguinte indagação: a comunidade escolar considera importante a implantação de bibliotecas nas instituições de ensino?

A partir desse questionamento, elaborou-se o seguinte objetivo geral: identificar a perspectiva dos alunos do Ensino Fundamental II, dos professores a da gestora de determinada escola pública quanto à implantação de uma biblioteca na referida instituição.

Para atingir esse objetivo elencaram-se os seguintes objetivos específicos:

a) traçar o perfil dos alunos, dos professores e da gestora dessa instituição;

b) detectar a importância da biblioteca escolar segundo a concepção desse grupo;

c) verificar o grau de importância do profissional bibliotecário no âmbito escolar segundo a percepção da comunidade estudada.

A abordagem desse assunto é de grande interesse para a classe bibliotecária, que ganharia muito mais espaço com a ocupação dessas instituições, ainda pouco exploradas por esses profissionais. A própria comunidade escolar (alunos, professores e outros funcionários da escola) também se beneficiaria bastante com a implantação de bibliotecas e inserção de bibliotecários nesses ambientes, pois teria melhores serviços de informação disponíveis e profissionais capacitados trabalhando a seu favor.

\section{A IMPORTÂNCIA DA BIBLIOTECA ESCOLAR E DA ATUAÇÃO DO BIBLIOTECÁRIO}




\section{Bibliocantos}

A criação da imprensa de Gutenberg, no século XV, proporcionou ao livro a mudança de uma fase de produção artesanal para uma fase comercial, tornando-o acessível às camadas sociais menos favorecidas. O invento da imprensa foi um momento de grande significância para a história do livro e das bibliotecas, pois a partir daí, com o intenso crescimento documental, as bibliotecas se multiplicaram e tornaram-se acessíveis para muitos. Se antes eram espaços exclusivos para custódia e conservação dos materiais de informação, hoje a biblioteca assume a função de difusora do conhecimento e da cultura.

Dentre os vários tipos de bibliotecas existentes, a biblioteca escolar, por estar voltada ao processo de formação educacional básico do cidadão, é um dos tipos que mais necessitam de atenção. O uso inadequado ou o não uso dessas bibliotecas é algo comum nas instituições públicas do país. A maior parte das escolas não dispõe de espaços como esses, mas geralmente quando possuem, são utilizados de forma precária, não servindo de base ao cumprimento de seu papel social no contexto educacional.

Para Castrillon (1985 apud MAYRINK, 1991. p. 304) a biblioteca escolar é:

[...] uma instituição do sistema social que organiza materiais bibliográficos, audiovisuais e outros meios e os coloca à disposição de uma comunidade educacional. Constitui parte integral do sistema educativo e participa de seus objetivos, metas e fins. A biblioteca escolar é um instrumento de desenvolvimento do currículo e permite o fomento da leitura e a formação de uma atividade científica; constitui um elemento que forma o indivíduo para a aprendizagem permanente, estimula a criatividade, a comunicação, facilita a recreação, apoia os docentes em sua capacitação e lhes oferece a informação necessária para a tomada de decisões em aula. Trabalha também com os pais de família e com outros agentes da comunidade.

Nota-se claramente que, além de servir como instrumento de apoio pedagógico e suporte a pesquisas, a biblioteca escolar atua prioritariamente na formação básica do cidadão, ensinando-o desde cedo os valores sociais e o exercício da cidadania. Evidencia-se também que esse ambiente não oferece 


\section{Dibliocantos}

subsídio apenas para alunos, mas para toda a comunidade escolar, formada por professores, estudantes e seus pais.

É consenso entre os educadores que as ações pedagógicas fluem melhor quando se tem na escola uma biblioteca dinâmica e bem estruturada. A biblioteca então aparece no contexto escolar como um espaço capaz de melhorar significativamente a qualidade da educação. Uma escola sem biblioteca é considerada uma instituição inacabada e nunca irá exercer por completo seu papel na formação do aluno.

Conforme citadas por Silva, Giansante e Rodringues (2008), a biblioteca escolar assume duas funções essenciais. A primeira está relacionada ao planejamento de todas as atividades da escola, dando suporte a professores e alunos. A outra está ligada ao papel de centro cultural da comunidade, fornecendo subsídios para recreação e socialização com diversos grupos.

A biblioteca escolar deve ser um espaço motivador, onde professores e bibliotecários possam interagir de modo a proporcionar um ambiente favorável ao desenvolvimento sociocultural do aluno. Oliveira (2009) relata que a biblioteca escolar deve ser um local onde os alunos adquiram o gosto pela leitura, aprendam se expressar, a realizar pesquisas individualmente, a ter momentos de recreação e consigam com a ajuda dos bibliotecários satisfazerem suas necessidades de informação.

Além disso, deve ser um local atrativo, que permita ao aluno desenvolver suas atividades de forma adequada, com conforto e tranquilidade. Tratar bem o usuário é o primeiro passo a ser dado para promover o uso desse espaço. Um usuário que é bem atendido e que tem a suas necessidades informacionais satisfeitas, nunca deixará de frequentar a biblioteca.

Para o desenvolvimento das competências informacionais, culturais, sociais e educativas nos seus usuários, é necessário que a biblioteca escolar cumpra os seguintes objetivos:

a) apoiar e intensificar a consecução dos objetivos educacionais definidos na missão e no currículo da escola; 


\section{Bibliocanto}

b) desenvolver e manter nas crianças o hábito e o prazer da leitura e da aprendizagem, bem como o uso dos recursos da biblioteca ao longo da vida;

c) oferecer oportunidades de vivências destinadas à produção e uso da informação voltada ao conhecimento, à compreensão, imaginação e ao entretenimento;

d) apoiar todos os estudantes na aprendizagem e prática de habilidades para avaliar e usar a informação, em suas variadas formas, suportes ou meios, incluindo a sensibilidade para utilizar adequadamente as formas de comunicação com a comunidade onde estão inseridos;

e) prover acesso em nível local, regional, nacional e global aos recursos existentes e às oportunidades que expõem os aprendizes a diversas ideias, experiências e opiniões;

f) organizar atividades que incentivem a tomada de consciência cultural e social, bem como de sensibilidade;

g) trabalhar em conjunto com estudantes, professores, administradores e pais, para o alcance final da missão e objetivos da escola;

h) proclamar o conceito de que a liberdade intelectual e o acesso à informação são pontos fundamentais à formação de cidadania responsável e ao exercício da democracia;

i) promover leitura, recursos e serviços da biblioteca escolar junto à comunidade escolar e ao seu derredor. (MANIFESTO..., 2000, p. 2)

Observando esses objetivos, é possível afirmar que as bibliotecas escolares no Brasil ainda estão longe de atingi-los. Entretanto se fossem cumpridos a rigor a situação da educação no país, que só faz piorar, melhoraria significativamente. Afinal, esse tipo de biblioteca assume papel fundamental na educação dos jovens. É notável que as funções desempenhadas por esses ambientes estão voltadas para o âmbito cultural, informacional, recreativo e educativo. Daí a importância da harmonia entre escola e biblioteca, pois seus objetivos são interligados e só a partir dessa união podem ser cumpridos adequadamente.

O contato inicial dos alunos com a biblioteca escolar irá refletir no indivíduo o desenvolvimento do gosto pela pesquisa. Pois, a partir dos primeiros contatos com essa unidade de informação, os estudantes irão despertar os seus desejos pela obtenção do conhecimento e na medida em que forem utilizando os recursos disponíveis, estarão se capacitando para o uso das fontes de informação em qualquer ambiente, habilitando-se até mesmo ao uso de outros tipos de bibliotecas. 


\section{Dibliocantos}

O incentivo à leitura é outro importante papel desempenhado pela biblioteca escolar. A prática da leitura deve começar desde a infância e muitas escolas negligenciam essa tarefa. Talvez, uma das principais causas disso seja a falta de consideração para com o uso da biblioteca escolar, visto que apenas uma minoria das escolas públicas possui e utiliza de fato esses ambientes.

Silva e Araújo (2003) afirmam que a biblioteca escolar deve estar diretamente relacionada com a escola para complementar as atividades realizadas em sala, desempenhando importante papel na formação do hábito de leitura. Relatam ainda que sua principal finalidade é a de fornecer material bibliográfico para professores e alunos de uma determinada escola.

O desenvolvimento das atividades da biblioteca deve estar de acordo com o interesse de seus usuários. Isso requer um planejamento integrado entre bibliotecários e professores, pois não adianta o profissional responsável pela unidade de informação criar uma série de serviços para instigar o desenvolvimento intelectual do estudante se o professor não participa ativamente disso.

É papel do professor, estimular o uso da biblioteca e suas fontes de informação, juntamente com o bibliotecário. Quinhões (1998, p. 4) enumera uma variedade de atividades desenvolvidas na biblioteca, que podem atrair um grande número de clientes e incitar a prática da leitura:

[...] clubes de leitura, criação de histórias, dramatização, varal de poesias, festivais artísticos, debates e palestras, concursos, hora do conto, janela mágica, tarde de autógrafos e outras atividades que os alunos sugerirem. Os professores de classe podem ainda realizar na Biblioteca Escolar atividades de literatura, orientação no uso de dicionários, enciclopédia e índices, devem ensinar a fazer resumos etc. Para estas ações, será necessário o livre acesso às estantes, aos fichários e catálogos o que levará o usuário a descobrir muito além do procurado.

A Lei 12.244 de 24 de maio de 2010 prevê, até o ano de 2020, a existência de bibliotecas, com acervo composto de pelo menos um exemplar para cada aluno matriculado, em todos os sistemas de ensino do país, seja público ou privado, respeitando os preceitos relativos à profissão do bibliotecário. Para efeitos dessa lei, considera-se biblioteca escolar a coleção de livros, materiais vídeo-gráficos e 


\section{(2aibliacantosas}

documentos registrados em qualquer suporte destinados a consulta, pesquisa, estudo ou leitura (BRASIL, 2010).

Espera-se com o cumprimento dessa lei que bibliotecários possam, de fato, ocupar esses espaços os quais Ihes são de direito e dessa forma contribuir com a melhoria do nível de ensino do país. A biblioteca escolar está diretamente relacionada ao contexto educacional, por isso, é indispensável, a presença do bibliotecário nesses locais. Esse profissional possui o conhecimento necessário para mediar o acesso à informação e satisfazer as necessidades informacionais da comunidade, além de ser capaz de promover a disseminação da cultura e do conhecimento.

Sob a visão de Orelo e Cunha (2013), além dos conhecimentos em processamento técnico e mediação da informação, o bibliotecário deve possuir habilidades em gestão da informação, ter um perfil dinâmico, com domínio das Tecnologias de Informação e Comunicação (TIC), preocupando-se sempre com a continuidade de sua educação.

Para um bom atendimento das necessidades de informação de seus usuários, cabe ao bibliotecário desempenhar as seguintes funções dentro da unidade de informação:

[...] proporcionar acesso à informação, às ideias que servem como portas de acesso ao conhecimento, ao pensamento e à cultura; proporcionar apoio essencial à formação contínua, para a tomada de decisão independente; contribuir para o desenvolvimento e a manutenção da liberdade intelectual ajudando assim a preservar os valores democráticos fundamentais universais; adquirir, preservar e disponibilizar a mais ampla variedade de documentos, refletindo a pluralidade da sociedade; assegurar que a seleção e a disponibilidade dos documentos e dos serviços sejam regidas por considerações de natureza profissional e não por critérios políticos, morais ou religiosos; adquirir, organizar e difundir a informação livremente; opor-se a qualquer forma de censura e disponibilizar os seus documentos, instalações e serviços a todos os utilizadores, de forma equitativa. (SALES, 2004, p. 44)

As tarefas do bibliotecário escolar são classificadas por Litton (1974) em três grupos principais: administrativas, técnicas e educacionais. 


\section{(2aibliacantos}

As atividades administrativas estão ligadas ao planejamento do ambiente, a supervisão do pessoal, a distribuição das tarefas, a gestão das coleções e a todas as outras atividades voltadas para a área administrativa.

Já as tarefas técnicas se relacionam com o tratamento da informação para que essa possa ser recuperada e usada de forma eficiente pela comunidade atendida. Nessas atividades estão incluídos os processos de catalogação, classificação, indexação e outros relacionados ao tratamento documental.

Por último, a categoria de tarefas educacionais, considerada por muitos a mais importante desse grupo, abrange o caráter humanístico, educacional e cultural da profissão. Incluem-se nesse grupo as atividades de incentivo à leitura, o planejamento junto com os professores e a comunidade escolar, a seleção de materiais educativos, a preocupação com o processo de ensino-aprendizagem e muitas outras atividades voltadas ao contexto educacional.

Deve-se atentar para que todas as tarefas desempenhadas pelo bibliotecário estejam relacionadas com a missão e os objetivos da escola e propiciem o uso adequado das fontes de informação existentes e o desenvolvimento do pensamento crítico nos alunos. Espera-se então que ele cumpra as seguintes atividades:

a) analise os recursos e as necessidades de informação da comunidade escolar;

b) formule e promova políticas para o desenvolvimento dos serviços;

c) desenvolva políticas e sistemas de aquisição para os recursos da biblioteca;

d) catalogue e classifique documentos e recursos em geral;

e) promova a utilização da biblioteca;

f) apoie alunos e professores na utilização de recursos da biblioteca e de tecnologia da informação;

g) dê respostas a pedidos de referência e de informação utilizando os materiais adequados;

h) promova programas de leitura e eventos culturais;

i) participe de atividades de planificação relacionadas com a gestão do currículo;

j) participe na preparação, promoção e avaliação de atividades de aprendizagem;

l) promova a avaliação de serviços de biblioteca enquanto componente normal e regular do sistema de avaliação global da escola;

m) construa parcerias com organizações externas;

n) prepare e aplique orçamentos; 


\section{DBibliocantos.}

o) conceba planejamento estratégico;

p) faça a gestão e a formação da equipa da biblioteca. (DIRETRIZES..., 2002, p. 13)

Evidencia-se que o bibliotecário é um agente transformador social com importância comprovada no espaço educacional. Além das competências em informação aprendidas ao longo de sua formação acadêmica, também desenvolveu habilidades educacionais adaptáveis ao ambiente escolar. A integração profissional entre bibliotecário e professor é a melhor maneira de proporcionar uma educação de qualidade nas escolas públicas.

\section{CARACTERIZAÇÃO DO AMBIENTE DA PESQUISA}

O estabelecimento de ensino onde se passou a pesquisa está localizado na periferia do município de João Pessoa e atende aos alunos do Ensino Fundamental, $1^{\circ}$ ao $9^{\circ}$ ano, na modalidade regular e Educação de Jovens e Adultos (EJA). No período da manhã funciona do $6^{\circ}$ ao $9^{\circ}$ ano (Ensino Fundamental II), já o da tarde compreende os alunos do $1^{\circ}$ ao $5^{\circ}$ ano (Ensino Fundamental I), por fim, o turno da noite abrange os alunos da modalidade EJA, da $5^{\mathrm{a}}$ a $8^{\mathrm{a}}$ série.

No ano de 2014, tinha na Escola um total de 355 (trezentos e cinquenta e cinco) discentes matriculado e 18 (dezoito) docentes lotados, distribuídos nos três turnos. O turno da manhã era composto 173 (cento e setenta e três) alunos e 08 (oito) professores. Já o período da tarde era formado por 97 (noventa e sete) alunos e 05 (cinco) professores. Por fim, o turno da noite possuía 85 (oitenta e cinco) alunos e 07 (sete) professores. A soma do número de professores por turno é maior do que o total geral porque existiam dois professores que ministravam disciplinas nos turnos manhã e noite.

A estrutura física da escola é precária, com espaço insuficiente para desempenhar muitas atividades que seriam relevantes para a educação dos alunos. Não existe um local adequado para armazenar o acervo. Atualmente, está na sala dos professores empilhados no chão e nas estantes sem qualquer preocupação com a organização, conforme mostra a figura 01 . 


\section{DBibliocantos}

Figura 01 - Acervo da Escola

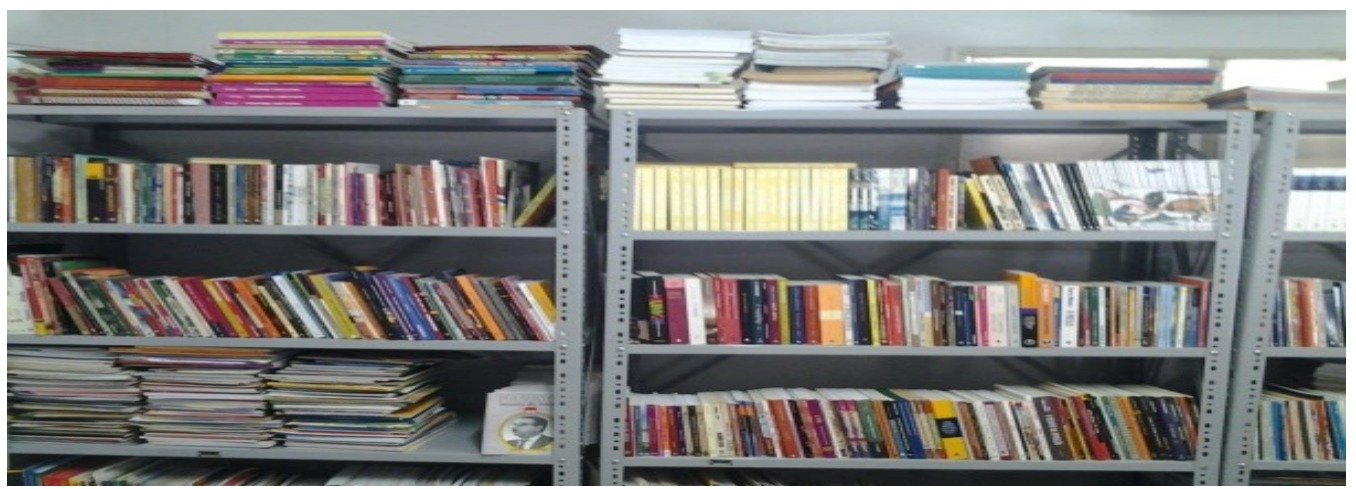

Fonte: Dados da pesquisa, 2014.

Devido a essa falta de espaço e de organização, os livros são subutilizados pela comunidade, pois é impossível encontrar a obra desejada. A superlotação nas prateleiras acaba ainda danificando os materiais informacionais. Todas essas obras chegam à escola através do Ministério da Educação e Cultura (MEC), mesmo sem existir uma biblioteca.

\section{PERCURSO METODOLÓGICO}

Com base no alcance dos objetivos propostos, esta pesquisa é de nível descritivo com abordagem qualitativa. Devido a uma série de vantagens explicitadas por Marconi e Lakatos (2003), dentre elas: economia de tempo, obtenção de grande número de dados, respostas rápidas e precisas, maior segurança, menor risco de distorção, entre outras, o questionário foi o instrumento de coleta de dados utilizado.

Sua aplicação ocorreu entre os dias 12 e 13 do mês de maio do ano de 2014, no turno da manhã, na própria escola analisada. Uma semana antes de aplicar essa ferramenta, realizou-se um pré-teste com três alunos e um professor da Escola, cuja finalidade foi verificar se o nível do vocabulário e a cobertura das questões se adequavam ao público pesquisado. Aos alunos, priorizou-se o uso de questões fechadas, já com os professores e a gestora, utilizou-se questões abertas. 


\section{a Bibliocantos}

De um total de 173 (cento e setenta e três) alunos do Ensino Fundamental II, 35 (trinta e cinco) responderam ao questionário, o que corresponde a $20,2 \%$ do universo. Quanto aos professores que ministram aulas aos alunos do $6^{\circ}$ ao $9^{\circ}$ ano, de um total de oito, cinco responderam ao questionário. Essa amostragem equivale a $62,5 \%$ do universo. Também foi aplicado um questionário à diretora da Escola.

Como pretendeu-se analisar a percepção de um determinado grupo de pessoas, entende-se que o delineamento da pesquisa seja levantamento de campo. Para Gil (2012), além de ser muito útil em estudos de opiniões e atitudes, os levantamentos são bastante adequados em pesquisas descritivas.

\subsection{Análise dos dados}

Para facilitar a organização dos resultados, os grupos estudados foram analisados separadamente, dessa forma, esta parte é dividida em subseções, cada uma tratando de um grupo específico.

\subsubsection{Alunos}

No primeiro momento buscou-se levantar o perfil dos alunos da escola. Como já mencionado, a amostra de 35 alunos que cursam o Ensino Fundamental II equivale a $20,2 \%$ do universo da pesquisa, tendo como gênero predominante o sexo feminino, constando um total de $54 \%$.

Com relação à faixa etária, 54\% possuem idades entre 10 aos 13 anos e $46 \%$ deles se enquadram na faixa etária dos 14 aos 18 anos. Apesar de alguns estudantes estarem com faixa etária acima dos padrões médios de idade/série estabelecidos pelas Diretrizes Básicas da Educação, a maioria possui idade ideal para cursar o Ensino Fundamental II.

Boa parte dos estudantes (74\%) afirmou que gosta de ler muito ou moderadamente. Pires (2012) afirma que a leitura é de extrema importância na preparação educacional e através dela o indivíduo irá desenvolver a maturidade para enfrentar a vida acadêmica quando ingressar no ensino superior. 


\section{a Bibliocantoo}

Quanto ao local onde adquiriram o gosto pela leitura, a família e a escola estão entre os ambientes mais significativos para os estudantes, com $34 \%$ cada. A internet foi indicada por $23 \%$ dos estudantes, mas não se preocupou nesta pesquisa em identificar quais conteúdos são acessados. A biblioteca obteve apena $9 \%$ das indicações, o que é preocupante e comprova que essas unidades de informação necessitam se adequar aos interesses da comunidade e promover de forma eficaz os serviços oferecidos.

Indagados se costumam frequentar bibliotecas, $74 \%$ responderam que não. Subentende-se que um dos motivos que os levam a não frequentarem bibliotecas é a inexistência de unidades em sua escola ou em algum lugar próximo de sua residência, além de fatores históricos e culturais como a influência da família.

Dentre os serviços que gostariam que fossem oferecidos pela biblioteca, $51 \%$ dos alunos gostariam de ter acesso à internet, outros $26 \%$ queriam que fossem oferecidos auxílios a pesquisas escolares e à normalização de trabalhos, enquanto $23 \%$ gostariam de ter acesso a gibis, revistas e jornais.

A respeito da utilidade da biblioteca, $40 \%$ consideram que ela serve para adquirir conhecimentos, $34 \%$ afirmam que é um local ideal para realizar pesquisas, $23 \%$ dizem que o espaço é útil para estudar e somente $3 \%$ alegam que a biblioteca serve para manter-se atualizado. Pode-se inferir então que os alunos acreditam na biblioteca como um lugar de grande relevância para a sua formação escolar, apontando-a como local de investigação, de pesquisa e de estudo. Isso mostra o quanto é necessária a implantação de bibliotecas nas escolas do país.

Sobre a atuação do bibliotecário, $97 \%$ dos alunos concordam que ele é o profissional mais indicado para administrar a biblioteca escolar. Apenas um aluno (3\%) não opinou e permaneceu neutro. Observa-se a importância de cumprir a Lei 12. 244 , de 24 de maio de 2010, que determina a obrigatoriedade de bibliotecas escolares com a presença do bibliotecário nas instituições de ensino do país, visto que a própria população concorda que a biblioteca só é bem utilizada se gerenciada por profissionais habilitados.

Constata-se ainda $83 \%$ dos alunos concordam que o bibliotecário é capaz de promover o uso da informação da melhor forma possível. Outros $11 \%$ 


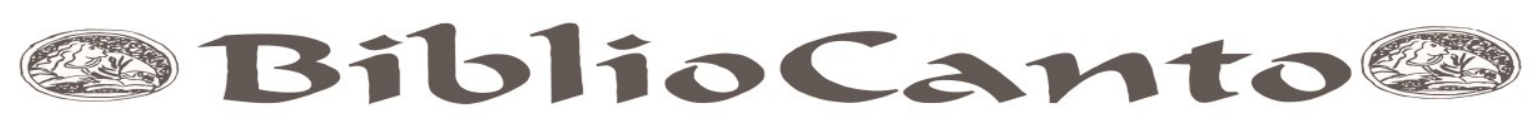

permaneceram neutros e apenas 6\% discordaram parcialmente dessa afirmativa. Apesar de os discentes não possuírem muito contato com bibliotecas, eles conhecem a importância do bibliotecário para uma formação escolar de qualidade.

Para finalizar o questionário dos alunos, quis-se saber sobre a importância do bibliotecário enquanto mediador da leitura e do conhecimento. Os dados mostram que $83 \%$ dos estudantes concordam que o principal agente de mediação da leitura e do conhecimento é o bibliotecário. $6 \%$ dos alunos questionados preferiram não opinar e $11 \%$ discordaram da afirmação.

\subsubsection{Professores}

O grupo de professores analisado é formado por cinco indivíduos que ministram as disciplinas de Língua Portuguesa, Matemática, Ciências naturais, Geografia e História. Desses, três são do sexo feminino (60\%) e dois são do sexo masculino (40\%). Com relação à idade, $60 \%$ deles se incluem na faixa etária dos 21 aos 40 anos, os outros $40 \%$ se enquadram na faixa etária de 41 a 60 anos.

Todos os professores possuem graduação, modalidade licenciatura plena, nas disciplinas em que atuam. A professora de Ciências naturais, além da licenciatura, é graduada em Pedagogia e também é a única que tem curso de pósgraduação em Psicopedagogia.

Sobre o tempo de atuação na Escola, a professora de Língua portuguesa está na repartição há apenas 01 (um) mês, o professor de História faz parte do quadro de funcionários há 03 (três) meses, o professor de Geografia atua na instituição há um ano e meio, já a professora de Ciências naturais dá aula na repartição há 13 (treze) anos e a de Matemática há 20 (vinte) anos.

O primeiro questionamento tratava da importância da biblioteca escolar, tendo obtido as seguintes respostas:

> Prof. 1: "[...] para a construção do conhecimento do alunado, é necessário realizarmos leituras e conhecer o mundo através dos livros";

> Prof. 2: "[...] é uma importante fonte de pesquisa para toda comunidade escolar"; 


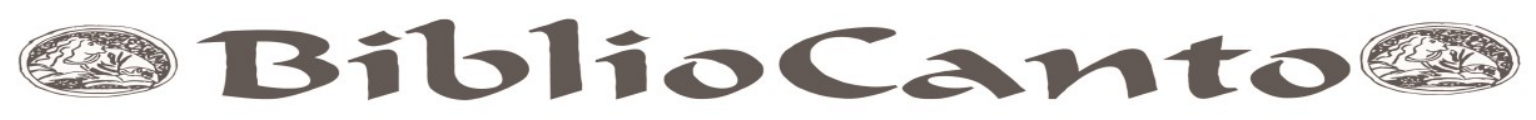

> Prof. 3: "Para facilitar o ensino-aprendizagem";

> Prof. 4: "[...] vai ajudar nossos alunos na realização dos trabalhos e nos estudos para as provas, ampliando ainda mais os seus conhecimentos";

> Prof. 5: "Para ajudar alunos e professores a adquirirem mais conhecimentos".

$\mathrm{Na}$ análise das respostas utilizou-se as simbologias Prof. 1, Prof. 2, Prof. 3, Prof. 4 e Prof. 5 para representar cada professor. Observa-se então que eles veem a biblioteca como um local de leitura, ensino, pesquisa, estudo, sendo considerada muito importante no processo de aquisição do conhecimento.

Questionados sobre os serviços que mais contribuem para o processo de ensino-aprendizagem, $80 \%$ deles julgaram que a orientação às pesquisas escolares e à normalização de trabalhos são os principais. Os outros $20 \%$ afirmaram que o empréstimo domiciliar é o que mais colabora nesse processo.

Acerca dos benefícios que a biblioteca gerenciada por um bibliotecário traria para a formação dos alunos, obteve-se o seguinte posicionamento:

$>$ Prof. 1: "A presença do profissional para orientar boas leituras seria uma influência positiva";

> Prof. 2: "Os alunos seriam muito beneficiados no desenvolvimento de suas pesquisas, estudos em grupo e nas relações de trabalho";

> Prof. 3: "Teriam oportunidade de conhecimento e compreensão de múltiplas leituras";

> Prof. 4: "Se beneficiariam principalmente em suas pesquisas";

Prof. 5: "Benefícios de mais conhecimentos adquiridos".

Com base nas respostas, percebe-se que a presença de uma biblioteca escolar bem organizada e coordenada pelo bibliotecário só traz benefícios para a comunidade. Seja na orientação de boas leituras, na compreensão de variados tipos de textos ou nas pesquisas escolares.

Todos os professores afirmaram que utilizaria em suas aulas a biblioteca, caso existisse uma na escola. Um dos papéis dos professores é educar e transferir conhecimentos aos alunos. Para cumprir esse papel é necessária uma constante 


\section{DBibliocantos}

busca em locais que proporcionem suporte informacional, como por exemplo, as bibliotecas escolares, se considerado o contexto da educação básica.

Outra questão perguntava se consideram o bibliotecário como o profissional ideal para administrar a biblioteca escolar e mais uma vez prevaleceu a unanimidade das respostas. Todos acreditam que sim, que o bibliotecário é o profissional mais qualificado para realizar essa tarefa, conforme mostram as justificativas:

> Prof. 1: "O bibliotecário possui o conhecimento necessário para orientar na escolha do livro".

> Prof. 2: "Ele está qualificado para administrar o acervo da biblioteca".

> Prof. 3: "O bibliotecário está apto a suprir as necessidades do educando".

> Prof. 4: "É o profissional mais capacitado para atender as necessidades do alunado".

Prof. 5: "Como é um profissional qualificado nessa área, tem a capacidade de atuar nela".

Os professores acreditam nas habilidades do bibliotecário, enquanto gestor de uma biblioteca escolar, pois assim como todos os profissionais que estudaram sobre uma determinada área do conhecimento, são os mais capacitados para atuarem nelas. A educação de qualidade depende de estruturas apropriadas, que possibilitem ao estudante ir além da sala de aula, viajar por mundos ricos em informações e conhecimentos, como as bibliotecas.

\subsubsection{Gestora}

A gestora atua na instituição há pouco mais de 01 (um) ano. A mesma é graduada em pedagogia, não possui pós-graduação, se encaixa na faixa etária entre 30 a 40 anos. Ela ainda afirmou que essa é sua primeira experiência enquanto gestora escolar.

Primeiramente questionou-se sobre a importância da biblioteca escolar e obteve-se a seguinte resposta:

a. "Certamente! Por ser um ambiente de descobertas e de exposição de conhecimento". 


\section{DBibliocantos}

São nesses ambientes que temos a oportunidade de conhecer o mundo que nos cerca. Para entendermos a sociedade que fazemos parte, precisamos nos debruçar cada vez mais no universo da leitura. As bibliotecas, como explicitado pela gestora da escola, são espaços fundamentais no processo de aquisição do conhecimento, uma vez que nelas existem os mais diversos materiais de informação.

Questionada sobre a contribuição da biblioteca escolar para o aprendizado dos alunos, ela respondeu que:

b. "Seu acervo possibilita, de acordo com um bom planejamento, enriquecer o ensino-aprendizagem".

Infere-se que ela acredita na responsabilidade da biblioteca no apoio aos docentes e confirma a importância desse espaço para o ensino-aprendizagem. As pesquisas escolares exigidas pelos professores são formas extensivas de aprimorar os ensinamentos repassados em sala de aula. Portanto para que o processo de ensino-aprendizagem seja alcançado de forma efetiva, é necessária a existência de ambientes apropriados e de profissionais qualificados apoiando esse fim.

Outro questionamento abordou a importância da biblioteca na prática docente e conseguiu-se observar, conforme citação abaixo, que para a gestora escolar a utilização adequada da biblioteca é capaz de melhorar significativamente a qualidade das aulas ministradas pelo corpo docente. Consequentemente, gerando benefícios para os alunos, pois com aulas mais dinâmicas e atrativas o ensinoaprendizagem se torna mais fácil.

c. "A adequada utilização da biblioteca enriquece as atividades dos professores, fortalece também suas estratégias e torna suas aulas mais atraentes".

Ela afirmou que ainda não existe nenhum projeto de implantação de uma biblioteca na Escola devido, principalmente, à falta de espaço físico. A carência de recursos financeiros também é um fator que dificulta a implantação. Cabe aos envolvidos no sistema escolar, seja professor, aluno, gestor, bibliotecário e até mesmo a própria comunidade, reivindicar às autoridades a construção desses espaços para uma educação de qualidade.

Sobre a atuação profissional do bibliotecário, ela respondeu que: 


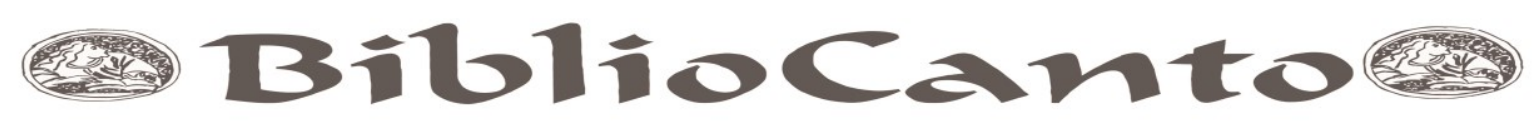

d. "O bibliotecário é a pessoa melhor preparada para tornar o espaço mais acessível, por ser um agente mediador entre a informação e quem a busca".

Fica claro que a gestora reconhece a importância do bibliotecário e, em linhas gerais, cita o principal papel desempenhado por esse profissional, que é o de agente mediador da informação. Para desempenhar com excelência sua função de mediador da informação, o bibliotecário precisa quebrar estereótipos existentes e começar a desenvolver o seu lado de agente social catalisador de mudanças.

Por fim, ela afirma o seguinte:

e. "Há uma urgente necessidade de difundir o uso de bibliotecas dentro das escolas para fortalecer a leitura também fora das instituições, visto que, esta ainda não faz parte das atividades diárias da maioria dos estudantes".

A implantação de bibliotecas nas escolas, segundo a gestora pesquisada, deve priorizar as atividades de incentivo à leitura. Portanto, cabe ao bibliotecário trabalhar em cima desse processo, estimulando essa prática e desenvolvendo nas pessoas o espírito de leitor. A leitura desenvolve nos indivíduos o pensamento crítico, a compreensão do mundo e os torna cidadãos conscientes de seus direitos e obrigações.

\section{CONSIDERAÇÕES FINAIS}

É fato que a educação pública no Brasil encontra-se defasada, a crise pela qual o país passa no setor educacional cresce cada dia mais. Professores mal pagos, ambientes de trabalho inadequados, ausência de recursos humanos e financeiros são apenas alguns fatores que comprovam esse caos. Diante de todo esse transtorno, as bibliotecas, principalmente as escolares são ambientes que estão esquecidos pelos governantes.

A presente pesquisa procurou identificar a perspectiva dos alunos do Ensino Fundamental II, dos professores a da gestora, de determinada escola pública localizada no município de João Pessoa, quanto à implantação de uma biblioteca na referida instituição. 


\section{DBibliocantos}

Ao analisar o grupo de alunos verificou-se que a maioria gosta de ler, entretanto não possuem um perfil de leitor. Apurou-se também que uma parcela significativa não costuma frequentar bibliotecas. Um dos principais motivos disso é a própria ausência delas no bairro. E talvez por serem muito jovens, seus responsáveis não permitam que se desloquem para outros bairros que possuam esses ambientes, é tanto que, aqueles que afirmaram que adquiriram o gosto pela leitura na biblioteca são a minoria; a maioria afirmou que o gosto pela leitura foi adquirido em casa.

Todos os alunos afirmaram que gostariam que existisse na sua escola uma biblioteca. Dentre os serviços mais interessantes na biblioteca, eles consideram que o principal é o acesso à internet. Frente ao intenso uso das tecnologias na sociedade atual, isso já era de se esperar. Com relação à utilidade das bibliotecas, muitos as veem como espaços onde as pessoas adquirem conhecimentos e realizam suas pesquisas.

Sobre a atuação do bibliotecário no âmbito escolar, os alunos acreditam que esse profissional é o mais qualificado para administrar uma biblioteca escolar. Concordam também que enquanto gestor da informação, ele é o principal responsável pela mediação da leitura e do conhecimento.

$\mathrm{Na}$ concepção dos professores, a biblioteca é um espaço de grande importância para o processo de aquisição de conhecimentos, além de contribuir com o desenvolvimento pedagógico dos alunos. Ainda sob a ótica desse grupo, uma biblioteca bem administrada proporciona inúmeros benefícios para a comunidade escolar, dentre eles, o aperfeiçoamento da prática de leitura, de pesquisa e de estudo. Todos foram categóricos em afirmar que utilizariam a biblioteca em suas aulas, caso existisse. Eles acreditam também que a atuação do bibliotecário escolar é muito relevante, pois esse profissional é capaz de influenciar positivamente as ações de ensino-aprendizagem.

A gestora escolar reconhece a necessidade de implantar uma biblioteca na escola, principalmente para desenvolver nos alunos o gosto pela leitura. Ela enxerga a biblioteca como instrumento de apoio às atividades dos docentes e da prática do ensino pedagógico. A mesma ainda revela que não existe nenhum projeto que vise à 


\section{a Bibliocantos}

construção de uma biblioteca devido, principalmente, à ausência de espaço físico na escola. No seu ponto de vista, o bibliotecário é a pessoa melhor preparada para tomar a frente de uma biblioteca escolar, uma vez que ele se capacitou para assumir essa função de mediador da informação.

De acordo com as considerações feitas a respeito desses grupos, é fato que tanto a gestora quanto alunos e professores almejam a implantação de uma biblioteca na Escola Estadual de Ensino Fundamental Henrique Dias. Todos acreditam que uma biblioteca bem estruturada e gerenciada por profissionais qualificados é capaz de melhorar significativamente o processo de ensinoaprendizagem e, através das práticas de leitura, despertar nos alunos o pensamento crítico e o desejo de adquirir conhecimentos, tornando-os aptos a exercer a cidadania de forma consciente. Entretanto, para a implantação de uma biblioteca nessa escola, é necessário o apoio dos governantes no sentido de destinarem mais recursos financeiros para ampliar as instalações da escola e reformar as que estão necessitando.

\section{The library under the gaze of the school community}

Abstract: It presents the vision of elementary school students II and the position of the teachers and the management about the library implementation need a certain public school, located in João Pessoa city. This is a qualitative study of descriptive level, where data collection is designed by applying questionnaires to 35 (thirty-five) students from 6th to 9th year, five teachers and school management. The results show that the research group aims to build a library in the educational institution. This should be well structured, offer diversified services to educational support, allowing access to information technology and managed by librarians. We conclude that, for the implementation of libraries in public schools, support is needed from governments in order to allocate more financial resources to reform and expansion of educational facilities.

Keywords: School library. Educational facilities. Librarians. Study users.

\section{REFERÊNCIAS}

BEHR, A.; MORO, E. L. S.; ESTABEL, L. B. Gestão da biblioteca escolar: metodologias, enfoques e aplicação de ferramentas de gestão e serviços de biblioteca. Ciência da Informação, Brasília, v. 37, n. 2, p. 32-42, 2008. Disponível 


\section{Dibliocantos}

em:<http://www.brapci.ufpr.br/brapci/_repositorio/2009/11/pdf_6083a438ce_0006793 .pdf>. Acesso em: 08 abr. 2014.

BRASIL. Lei $n^{\circ}$ 12. 244, de 24 de maio de 2010. Universalização das bibliotecas nas instituições de ensino do país. Palácio do Planalto - Presidência da República, Brasília, DF, 25 maio 2010. Disponível em:

<http://www.planalto.gov.br/ccivil_03/_Ato2007-2010/2010/Lei/L12244.htm>. Acesso em: 06 maio 2014.

CORREAA, E. C. D. et al. Bibliotecário escolar: um educador?. Revista ACB:

Biblioteconomia em Santa Catarina, Florianópolis, v. 7, n. 1, p. 107-123, 2002.

Disponível em:

<http://www.brapci.ufpr.br/brapci/_repositorio/2010/06/pdf_f4ddf6fc50_0011080.pdf>. Acesso em: 02 abr. 2014.

DIRETRIZES DA IFLA/UNESCO para bibliotecas escolares. Tradução Maria José Vitorino. São Paulo: IFLA, 2002.

ELY, N. H. Dimensões da biblioteca escolar no ensino fundamental. Revista ACB: Biblioteconomia em Santa Catarina, Florianópolis, v. 8, n. 1, p. 46-53, 2003.

Disponível em:

<http://www.brapci.ufpr.br/brapci/_repositorio/2010/06/pdf_4d14046509_0011110.pdf >. Acesso em: 08 abr. 2014.

GIL, A. C. Métodos e técnicas de pesquisa social. 6. ed. São Paulo: Atlas, 2012.

LITTON, G. Bibliotecas escolares. Buenos Aires: Bowker Editores Argentina, c1974.

MACEDO, N. D. (Org.). Biblioteca escolar brasileira em debate: da memória profissional a um fórum virtual. São Paulo: SENAC, Conselho Regional de Biblioteconomia - 8ª Região, 2005.

MANIFESTO IFLA/UNESCO para biblioteca escolar. Tradução Neusa Dias de Macedo. São Paulo: IFLA, 2000.

MARCONI, M. A.; LAKATOS, E. Fundamentos de metodologia científica. 5 ed. São Paulo: Atlas, 2003.

MAYRINK, P.T. Diretrizes para a formação de coleções de bibliotecas escolares. In: CONGRESSO BRASILEIRO DE BIBLIOTECONOMIA E DOCUMENTAÇÃO, 16., 1991, Salvador. Anais... Salvador: Associação Profissional dos Bibliotecários do Estado da Bahia, 1991. v.1, p. 304-314. 


\section{Bibliocanta}

OLIVEIRA, G. L. C. Biblioteca escolar: o acordar de um sonho para o ensino fundamental. 2009. 89f. Monografia (Graduação) - Curso de Graduação, Universidade Federal da Paraíba, João Pessoa, 2009.

ORELO, E. R. M.; CUNHA, M. F. V. O bibliotecário e a competência informacional. Informação \& Sociedade: Estudos, João Pessoa, v. 23, n. 2, p. 25-32, maio/ago. 2013. Disponível em:

<http://www.brapci.ufpr.br/brapci/_repositorio/2015/12/pdf_a7e6a217f7_0000013570. pdf>. Acesso em: 02 abr. 2014.

PIRES, E. A. N. A importância do hábito da leitura na universidade. Revista ACB: Biblioteconomia em Santa Catarina, Florianópolis, v. 17, n. 2, p. 365-381, jul./dez. 2012. Disponível em: <http://revistaacb.emnuvens.com.br/racb/article/view/846/pdf>. Acesso em: 13 maio 2014.

QUINHÕES, M. E. T. Biblioteca escolar: sua importância e seu espaço no sistema educacional do Estado do Rio de Janeiro. In: JORNADA NORTE/NORDESTE DE BIBLIOTECONOMIA E DOCUMENTAÇÃO, 2., SEMINÁRIO NORTE/NORDESTE DE BIBLIOTECAS ESCOLARES, 1., 1998. Recife, PE. Disponível em: <http://www.seict.facepe.pe.gov.br/jornado>. Acesso em: 02 abr. 2014.

SALES, F. O ambiente escolar e a atuação bibliotecária: o olhar da educação e o olhar da biblioteconomia. Enc. Bibli: R. Eletr. Bibliotecon. Ci. Inf., Florianópolis, v. 9, n. 18, p. 40-57, 2004. Disponível em:

<http://www.brapci.ufpr.br/brapci/_repositorio/2010/09/pdf_9c158d51c9_0011796.pdf >. Acesso em: 03 abr. 2014.

SILVA, A. P. B.; GIANSANTE, H. G.; RODRIGUES, W. J. Biblioteca escolar e a gestão escolar pública. In: SIMPÓSIO INTERNACIONAL DE EDUCAÇÃO, 2., 2008, Bauru, SP. Anais... Bauru, SP: USC, 2008.

SILVA, D. A.; ARAÚJO, I. A. Auxiliar de biblioteca: técnicas e práticas para formação profissional. 5. ed. Brasília: Thesaurus, 2003. 